\title{
Comparing Effectiveness Of Undergraduate Course Delivery: A Student Perspective
}

Robert J. Koenig, New York Institute of Technology, USA

\begin{abstract}
Higher education students can and do take courses delivered in a variety of ways. But, to date, little research has been done on the effectiveness of different delivery modes. This study sought to fill that void by comparing the effectiveness of three undergraduate course delivery modes: classroom, online, and video conference at a technical institute in a mid-Atlantic state. Students $(N=1,206)$ completed questionnaires on effectiveness, in terms of satisfaction, for each mode and on demographic characteristics. The questionnaire response rates were $74 \%$ for students. In terms of student satisfaction, the results revealed that classroom delivery was more effective than technologically delivery with online being slightly more effective than video conference. The results of this research should assist leaders in higher education to understand the benefits associated with different undergraduate course delivery modes. In addition, the study provides leaders with a useful tool for securing and applying this type of information when making decisions about the modes best suited to serve their academic communities.
\end{abstract}

\section{INTRODUCTION}

( n colleges and universities, students are increasingly exposed to a variety of modes of instructional delivery. Distance education has enjoyed renewed popularity with the advent of technological delivery through two main forms: online and video conference. However, if institutions of higher education invest in distance education using online and/or video conference delivery but do not assess the effectiveness of these approaches, the end result could be fiscally and academically detrimental.

To address the issue of determining the effectiveness of different instructional delivery methods, this study compared three modes for undergraduate education: classroom, online, and video conference. The methodology used for this study was an effectiveness analysis, which refers to the evaluation of alternatives according to their effects. Effectiveness was measured against a set of established criteria, from those recommended by the National Education Association (2000), the American Federation of Teachers (2000), and the American Distance Education Consortium (2003), in terms of satisfaction with the course delivery mode. The data were collected from one institution of higher education, a technical institute in a mid-Atlantic state, which had a long history of using all three delivery modes.

The role of distance education in the renewal of the wider university enterprise should depend on the effectiveness of present and future technologies. With the continuing shortage of funds to support higher education, institutions must not only maintain, but enhance their cost-effectiveness if they are to provide an attractive, sustainable instructional model (Daniel, 1999). The findings of this study can be used to assist institutional leaders in developing ways to assess and compare effectiveness of classroom delivery with technology-based delivery.

Research Site. The site institution for this study has a long history of using all three methods of course delivery. The institution has been teaching classroom-based courses for 50 years, has used video conference-based course delivery for nine years, and has used online-based course delivery for five years. This institution was selected because the students have the option of choosing the type of delivery mode they prefer and many students have experienced blended learning by availing themselves of more than one delivery mode. Additionally, this site was selected because the institution was convenient for the researcher and was willing to participate in the study. The selected institution agreed to support the study and granted permission to collect information from students. 
Effectiveness in Terms of Satisfaction. Based on the National Education Association's Benchmarks for Success in Internet-Based Distance Education (2000), the American Federation of Teachers Guidelines for General Practice (2000), and the American Distance Education Consortium's Guiding Principles for Distance Teaching and Learning (2003), effectiveness in terms of satisfaction was assessed from the student perspective. Satisfaction was judged by using a series of questionnaire items to determine how well the technology, the infrastructure, the course content, and instructional inter-activeness matched student and faculty needs.

The measures of effectiveness were developed by drawing upon factors derived from previous developed lists of crucial elements. For the selection of the factors to be used in this study, each factor included had to appear on at least two of the lists of effectiveness devised by the National Education Association (2000), the American Federation of Teachers (2000), and the American Distance Education Consortium (2003). Using the decision rule of at least two appearances, nine factors were identified as measures of satisfaction and, thus, by definition measures of effectiveness. These nine items were applied to the three undergraduate course delivery modes: classroom, online and video conference to assess satisfaction.

\section{Factors Related to Effectiveness of Course Delivery Modes}

1. Class size density

2. Utilization of educational resources

3. Enhancement and application of cognitive skills

4. $\quad$ Promotion of active participation by students

5. Interaction of instructor and students within learning environment

6. Allowance for student group collaboration

7. Recognition of different learning styles

8. Accommodation of diversity and multiculturalism

9. Effectiveness for learning course content.

Effectiveness. This study surveyed undergraduate students in fall 2006 to secure a measure of satisfaction with each delivery mode. The student questionnaire was distributed to students taking classroom courses $(n=596)$, students taking online courses $(n=500)$, and students taking video conference courses $(n=109)$.

The students $(N=1,205)$ to whom the questionnaires were distributed were selected by classes from those taking courses in five areas: accounting, business management, hospitality management, behavioral science, and English. These areas were selected for the study because courses offered in all these areas were available in each of the three modes.

Data Collection for Effectiveness. To collect information on effectiveness, short questionnaires were tailored for students for each of the three delivery modes for a total of three versions, which posed essentially the same questions. Of the items on the questionnaire, nine were based on the factors indicating satisfaction taken from the lists developed by national organizations. These items required responses that ranged from Strongly disagree to Strongly agree on a four-point Likert-type scale. Two items asked for comparisons between delivery mode pairs. Three items asked for information concerning familiarity in terms of number of courses taken with each delivery mode. The demographic information collected from students included: gender, age, race/ethnicity, academic major, year of study, and full-time status. An open-ended question completed the questionnaire, so respondents desiring to do so could express their opinions on different course delivery modes or on other issues.

Data Analysis. The data collected for effectiveness were compiled from the questionnaires that were completed by students for the three delivery modes. Each questionnaire measured effectiveness on nine factors in terms of satisfaction with class size density, utilization of educational resources, enhancement and application of cognitive skills, promotion of active participation by students, interaction of instructor and students within learning environment, allowance for student group collaboration, recognition of different learning styles, accommodation for diversity and multiculturalism and effectiveness for learning course content. These factors were supported by literature which suggested their importance and relevance to the educational learning environment. 
For each effectiveness item, respondents had the choice of one of four responses: strongly disagree, disagree, agree, and strongly agree. Strongly agree signified highly effective, whereas strongly disagree signified highly ineffective. Numerically, the responses were assigned values ranging from a low of "1" for strongly disagree to a high of " 4 " for strongly agree. The responses were tabulated for each item for students, and by each delivery mode: classroom, online, and video conference. Total effectiveness was calculated as the sum of the scores on the individual items and the means and standard deviations were calculated for each respondent group and for each delivery mode.

The original plan was to use Analyses of variance (ANOVAs) to test for differences on the total effectiveness by group (students) and by delivery mode (classroom, online, and video conference). Assumptions crucial to use of ANOVAs, normality and homogeneity of variance, were assessed but not all of these tests were met. As a result, $t$-tests were used to make the comparisons. All items on the questionnaire were weighted equally.

Utilizing questionnaire data for student preferences in terms of delivery mode were related to student demographic characteristics: gender, age, race/ethnicity, academic major, year of study, and full-time status. Chisquare tests were conducted to assess these relationships.

\section{FINDINGS}

\section{Demographics}

a. Gender of Students. To the questionnaire, 878 students provided useable responses. Of these, 383 were males $(44 \%)$ and 495 were females $(56 \%)$. This gender distribution varied from the composition of the site institution of 8,225 undergraduate students; 4,544 males (55\%), 3,315 females (40\%), and 366 unknowns (4\%). The unknowns were those students who did not check off the gender indication box when filing their admissions forms.

b. Race/Ethnicity of Students. In terms of race and ethnicity, Table 1 presents the breakdown for the participating students by frequency and percent. The categories used for the racial/ethic groups were African American, Asian, Caucasian, Hispanic, Pacific Islander, and Other for those not considering themselves to be included in the other groups. The largest racial/ ethnic student group participating in the study was Caucasian, followed by Asian, Other, Hispanic, African American, and Pacific Islander.

Table 1: Distribution of Students by Race/Ethnicity in Frequency and Percent

\begin{tabular}{ccc}
\hline Race/Ethnicity & Frequency & Percent \\
\hline African American & 74 & 8.4 \\
Asian & 181 & 20.5 \\
Caucasian & 369 & 41.7 \\
Hispanic & 109 & 12.3 \\
Pacific Islander & 11 & 1.2 \\
Other & 140 & 15.8 \\
\hline
\end{tabular}

c. Age of Students. The ranges in age used on the student questionnaire and the frequencies and percentages of responses are presented in Table 2. Five age ranges were used from a low of 18 years to a high of more than 40 years. Three-quarters of the students $(76 \%)$ were in the traditional college-aged group.

Table 2: Distribution of Students by Age Range in Frequency and Percent

\begin{tabular}{ccc}
\hline Age Range & Frequency & Percent \\
\hline & & 75.7 \\
18-25 years & 671 & 13.3 \\
26-30 years & 118 & 3.6 \\
31-35 years & 32 & 2.4 \\
36-40 years & 21 & 5.0 \\
\hline > 40 years & 44 & \\
\hline
\end{tabular}


d. Student Year. Frequencies and percentages for responding students by year are presented in Table 3. The respondents represented a good balance from each year: freshman, sophomore, junior, and senior, but the respondents were weighed more heavily towards the upper-division classes than the distribution of undergraduates within the institution.

Table 3: Distribution of students by Year in Frequency and Percent

\begin{tabular}{|c|c|c|}
\hline Year & Frequency & Percent \\
\hline Freshman & 237 & 27.8 \\
\hline Sophomore & 140 & 16.4 \\
\hline Junior & 181 & 21.2 \\
\hline Senior & 294 & 34.5 \\
\hline
\end{tabular}

e. Student Academic Major. The choice of academic majors of the responding students, in terms of frequencies and percentages, is presented in Table 4. The greatest number of the students, about twothirds, selected Other as their major. Hospitality Management was the next most frequent major.

Table 4: Distribution of Students by Major in Frequency and Percent

\begin{tabular}{ccc}
\hline Major & Frequency & Percent \\
\hline Accounting & & 2.5 \\
Business Administration & 22 & 7.9 \\
Hospitality Management & 70 & 16.7 \\
Behavioral Science & 148 & 5.2 \\
English & 46 & 1.7 \\
Other & 15 & 66.0 \\
\hline
\end{tabular}

f. Full-Time Status of Students. Among the students responding, 769 were enrolled full-time (87\%) and 119 were enrolled part- time (13\%), This compared with a total undergraduate student body in which 6,177 students enrolled full-time (75\%) and 2,048 students enrolled part-time (25\%).

\section{Response Rates for Questionnaires}

a. Student Questionnaires. For two delivery modes, classroom and video-conference, the return rates were $100 \%$ for the student questionnaires. For these modes, the questionnaires were distributed and collected in the classroom. The online mode had a lower return rate. These return rates by mode are presented in Table 5. The overall return rate for the student questionnaires was $74 \%$.

Table 5: Response Rates for Student Questionnaires

\begin{tabular}{lccc}
\hline \multicolumn{1}{c}{ Delivery Mode } & Number Requested & Number of Responses & Percent \\
\hline & & & \\
Classroom & 597 & 597 & $100 \%$ \\
Online & 500 & 182 & $36 \%$ \\
Video Conference $\quad 109$ & 109 & $100 \%$ \\
$\quad$ Total & 1,206 & 888 & $74 \%$ \\
\hline
\end{tabular}

b. Effectiveness of Three Delivery Modes In order to determine effectiveness in terms of satisfaction with the three delivery modes, classroom, online, and video conference, short questionnaires for each mode were tailored to students. The resulting student data did not meet all the requirements for using the ANOVA test 
to compare the results, particularly the equal variance requirement. However, in order to produce comparable results for student effectiveness, the decision was made to use $t$-tests for the analyses of both.

c. For students, 10 independent sample $t$-tests were conducted to examine if mean differences existed on the nine effectiveness measures (class size, education utilization, cognitive skills, student participation, interaction, collaboration, learning styles, diversity, and effective delivery) and on total effectiveness by mode (classroom vs. online; classroom vs. video conference, and online vs. video conference).

Each questionnaire ended with this invitation to the participating students: Any general or additional comments pertaining to [classroom or online or video conference] courses are welcome. Results from this open-ended question are summarized at the end of this section.

d. Student Effectiveness of Three Delivery Modes The means and standard deviations for each of the student effectiveness measures by mode are reported in Table 6.

Table 6: Means and Standard Deviations for Student Effectiveness by Mode: Classroom, Online, and Video Conference

\begin{tabular}{|c|c|c|c|c|c|c|}
\hline & \multicolumn{2}{|c|}{ Classroom } & \multicolumn{2}{|c|}{ Online } & \multicolumn{2}{|c|}{$\begin{array}{c}\text { Video } \\
\text { Conference }\end{array}$} \\
\hline & M & SD & $\mathbf{M}$ & SD & $\mathbf{M}$ & SD \\
\hline Class Size & 2.90 & 0.74 & 3.21 & 0.79 & 2.74 & 0.79 \\
\hline Education Utilization & 3.13 & 0.67 & 2.84 & 0.82 & 2.70 & 0.81 \\
\hline Cognitive Skills & 3.21 & 0.60 & 2.90 & 0.81 & 2.78 & 0.75 \\
\hline Student Participation & 3.34 & 0.67 & 2.82 & 0.93 & 2.65 & 0.81 \\
\hline Instructor Interaction & 3.43 & 0.63 & 2.65 & 0.89 & 2.57 & 0.83 \\
\hline Student Collaboration & 3.28 & 0.66 & 2.51 & 0.94 & 2.58 & 0.80 \\
\hline Learning Style & 3.03 & 0.66 & 2.81 & 0.78 & 2.80 & 0.74 \\
\hline Diversity & 3.22 & 0.64 & 2.81 & 0.91 & 2.84 & 0.75 \\
\hline Effective Delivery & 3.25 & 0.58 & 2.79 & 0.87 & 2.67 & 0.76 \\
\hline Total Effectiveness & 3.20 & 0.43 & 2.81 & 0.65 & 2.71 & 0.56 \\
\hline
\end{tabular}

In making the comparisons, Levene's tests of equal variances were significant, thus unequal error variance $t$-tests were used on the specified variables. The results for an independent sample $t$-test on student effectiveness comparing classroom vs. online modes are presented in Table 7, for classroom vs. video conference in Table 8, and for online vs. video conference in Table 9. Each table is followed by a discussion of the significant findings.

Table 7: T-Tests for Student Effectiveness by Mode: Classroom vs. Online

\begin{tabular}{lccc}
\hline \multicolumn{1}{c}{ Effectiveness Measures } & $\boldsymbol{t}$ & df & Sig. \\
\hline & & & \\
Class Size & -4.68 & 286 & .000 \\
Education Utilization & 4.37 & 260 & .000 \\
Cognitive Skills & 4.68 & 243 & .000 \\
Student Participation & 6.91 & 241 & .000 \\
Instructor Interaction & 10.98 & 237 & .000 \\
Student Collaboration & 10.27 & 239 & .000 \\
Learning Style & 3.46 & 264 & .001 \\
Diversity & 5.61 & 239 & .000 \\
Effective Delivery & 6.81 & 233 & .000 \\
Total Effectiveness & 7.36 & 223 & .000 \\
\hline
\end{tabular}

Note. Because a total of nine $t$-tests were run, the alpha level of .05 was adjusted to .01 .

The results of the analysis, presented in Table 7, revealed significant differences on all the effectiveness measures between classroom and online delivery with students expressing greater satisfaction on all measures. 
However, on class size, the mean for classroom students was significantly smaller, which suggested that classroom delivery $(M=2.90)$ did not work as well for students as online delivery $(M=3.21)$ in accommodating any number of students. On all other measures, classroom students were significantly more favorably disposed than online students.

Table 8: $T$-Tests for Student Effectiveness by Mode: Classroom vs. Video Conference

\begin{tabular}{lccc}
\hline \multicolumn{1}{c}{ Effective Measures } & $\boldsymbol{t}$ & df & Sig. \\
\hline Class Size & & & .043 \\
Education Utilization & 2.03 & 703 & .000 \\
Cognitive Skills & 5.26 & 136 & .000 \\
Student Participation & 5.62 & 134 & .000 \\
Instructor Interaction & 8.31 & 135 & .000 \\
Student Collaboration & 10.32 & 132 & .000 \\
Learning Style & 8.64 & 137 & .002 \\
Diversity & 3.09 & 141 & .000 \\
Effective Delivery & 5.42 & 699 & .000 \\
Total Effectiveness & 7.63 & 132 & .000 \\
\hline Note. Because a total & 8.49 & 131 & \\
\hline
\end{tabular}

Note. Because a total of nine $t$-tests were run, the alpha level of .05 was adjusted to .01 .

The results of the analysis, presented in Table 8 , revealed significant differences on all effectiveness measures, reported by students between classroom delivery and video conference delivery, except one. This indicated that the classroom students rated various effectiveness aspects of their courses higher than did the video conference students. However, on class size the difference was not significant, even though students found classroom delivery $(M=2.90)$ slightly more accommodating to any number of students than did students in the video conference delivery mode $(M=2.74)$.

Table 9: $T$-Tests for Student Effectiveness by Mode: Online vs. Video Conference

\begin{tabular}{lccc}
\hline \multicolumn{1}{c}{ Effectiveness Measures } & $\boldsymbol{t}$ & df & Sig. \\
\hline & & & \\
Class Size & 4.89 & 289 & .000 \\
Education Utilization & 1.46 & 289 & .147 \\
Cognitive Skills & 1.27 & 289 & .207 \\
Student Participation & 1.63 & 288 & .104 \\
Instructor Interaction & 0.79 & 288 & .431 \\
Student Collaboration & -0.65 & 256 & .517 \\
Learning Style & 0.15 & 288 & .880 \\
Diversity & -0.34 & 260 & .733 \\
Effective Delivery & 1.16 & 289 & .249 \\
Total Effectiveness & 1.29 & 280 & .198 \\
\hline
\end{tabular}

Note. Because a total of nine $t$-tests were run, the alpha level of .05 was adjusted to .01 .

The results of the analysis presented in Table 9 revealed only one significant difference between the effectiveness of online and video conference delivery, as determined by students. This suggested in the opinion of students that video conference delivery was less adaptable to accommodating any number of students than was the online delivery. Otherwise, no significant differences on effectiveness were found between these two distance education delivery modes.

Student Comments on Classroom Delivery. A positive common theme among the students taking classroom courses was that classroom delivery allowed students to concentrate on and to understand the material and that greater interaction occurred between the students and the instructor. Classroom delivery allowed students to "stand up" and demonstrate physical actions and presentations, more easily than either online or video conference deliveries could permit. Classroom delivery was more accommodating for international students who needed more 
help because of language differences. Through interactions in the classroom, instructors could get a better understanding of their students and how to address students' individual needs. A majority of the students expressed the opinion that face-to-face conventional classroom courses were by far the best way to learn.

Some common negative thoughts expressed by students were that some instructors promoted classroom discussion and participation, while others did not want anyone to speak or to ask questions until told to do so.

Student Comments on Online Delivery. A positive common thought shared by many students about online delivery was the flexibility of fulfilling the course work around personal time schedules. Many students noted that online delivery accommodated various work hours, as well as family commitments and obligations, and overcame the difficulty of having to come physically to class. In addition, some students commented that they enjoyed online delivery because it provided an opportunity to participate more than they would have in a classroom. Online delivery also provided an opportunity for students to learn at their individual rates. However, a large number of students noted the success of the online delivery largely depended upon the instructor; some instructors were very active, where others were not.

One common negative reaction from students was that they found the institutional policy requiring a minimum of 2.5 GPA for students to take online courses unfair, especially because this requirement did not apply to those taking classroom or video conference courses. Student also noted the concern that other online students find ways to cheat on examinations more easily than students in classroom or video conference courses. One student said, "How does an instructor know who is taking the exam, and if more than one student are together when they are doing the exam."

Additional concerns from online students were that the online course itself can be confusing in the way it is set up for students, because many instructors arranged their course sites quite differently. Lack of personal contact with the instructor was another concern voiced by online students. The online mode was seen as very impersonal. At times there was little or no communication between the instructor and the students, leaving students feeling alienated and isolated.

Student Comments on Video Conference Delivery. A common positive reaction among the students using video conference delivery was that it saved commuting time. Also, the video conference mode provided students with real world experience of teleconferencing, which is used in the business world. Many students also commented that if the instructor was very good at communicating and keeping the students involved in the subject matter, the class was equally as engaging as traditional classroom delivery.

A common negative reaction among many video conference students was that instructors often had difficulty operating the technology and getting the initial set-up of the class started on time. Other negative comments pertained to difficulties in hearing the instructor, poor visibility for students, and lack of clarity of faculty on screen. Additionally, many students did not like the idea of seeing themselves on large monitors viewed at other campus sites. Video conference students noted that they did not like having an instructor teaching from afar, and not being in the same classroom with them. Students stated that video conference delivery lacked the type of interaction with the instructor and other students that was possible in the traditional classroom.

Demographic Characteristics of Students. The demographic characteristics of students were compared for the three course delivery modes to determine if student preference for mode was related to these various characteristics. Because almost all the data on characteristics were nominal, a nonparametric statistical test, Pearson chi-square, was used in these analyses. Six chi-squares were conducted to examine whether significant relationships existed between mode: classroom, online, and video conference, and demographics characteristics: gender, race/ethnicity, age, year in school, academic major, and full-time status. Standardized residuals (greater than 2) were used to pinpoint the source of significant differences.

Gender of Student. The results of the observed and expected frequencies computed to examine whether significant relationships existed between the gender of students and delivery mode choice are presented in Table 10. 
Table 10: Chi-Square Test of Observed and Expected Frequencies by Gender of Student and Delivery Mode

\begin{tabular}{lcccc}
\hline \multicolumn{1}{c}{ Gender } & Class- room & Online & Video & Total \\
\hline & & & & 383 \\
Male & 275 & 68 & 40 & \\
Expected Count & 258.2 & 77.6 & 47.1 & \\
Standardized Residual & 1.0 & -1.1 & -1.0 & 495 \\
& & & 68 & \\
Female & 317 & 110 & 60.9 & .9 \\
Expected Count & 333.8 & 100.4 & & 878.0 \\
Standardized Residual & -.9 & & 1.0 & 878.0 \\
Total Count & & 108.0 & \\
Expected Count & 592.0 & & & \\
\hline
\end{tabular}

$\chi^{2}=5.96, d f=6, N=878, p=.051$

The highest numbers of both male and female students were in classroom, as compared to online and video conference delivery. The resulting significance of $p=.051$ for this test most likely was the result of the large sample size, because the follow-up analysis of the standardized residuals failed to identify a gender by mode configuration that contributed meaningfully to the chi-square result. It was concluded, therefore, that no significant relationship existed between gender and course delivery mode.

Race/ Ethnicity of Student. The results of the observed and expected frequencies for the race/ethnicity of students by delivery mode are presented in Table 11. Caution should be given to interpretation, because two cells (11\%) had expected counts of less than 5 .

The results indicated no significant relationship existed when comparing race/ethnicity with delivery mode preference.

Table 11: Chi-Square Test of Observed and Expected Frequencies by Race/Ethnicity of Student and Delivery Mode

\begin{tabular}{|c|c|c|c|c|}
\hline Race/Ethnicity & Class- room & Online & Video & Total \\
\hline African American & 48 & 15 & 11 & 74 \\
\hline Expected Count & 49.9 & 15.1 & 9.0 & \\
\hline Standardized Residual & -.3 & .0 & .7 & \\
\hline Asian & 126 & 31 & 24 & 181 \\
\hline Expected Count & 122.0 & 36.9 & 22.1 & \\
\hline Standardized Residual & .4 & -1.0 & .4 & \\
\hline Caucasian & 241 & 79 & 49 & 369 \\
\hline Expected Count & 248.8 & 75.1 & 45.1 & \\
\hline Standardized Residual & -.5 & .4 & .6 & \\
\hline Hispanic & 74 & 22 & 13 & 109 \\
\hline Expected Count & 73.5 & 22.2 & 13.3 & \\
\hline Standardized Residual & .1 & .0 & -.1 & \\
\hline Pacific Islander & 7 & 2 & 2 & 11 \\
\hline Expected Count & 7.4 & 2.2 & 1.3 & \\
\hline Standardized Residual & -.2 & -.2 & .6 & \\
\hline Other & 100 & 31 & 9 & 140 \\
\hline Expected Count & 94.4 & 28.5 & 17.1 & \\
\hline Standardized Residual & .6 & .5 & -2.0 & \\
\hline Total & & & & 884 \\
\hline Expected Count & 596 & 180 & 108 & 884 \\
\hline
\end{tabular}


Age Range of Student. A Pearson chi-square test was conducted to examine whether significant relationships existed between student age range and delivery mode. The observed and expected frequencies for each cell are reported in Table 12. Caution should be taken when interpreting the results, due to the fact three cells (20\%) had expected counts of less than 5 .

Table 12: Chi-Squared Test of Observed and Expected Frequencies by Age Range of Student and Delivery Mode

\begin{tabular}{|c|c|c|c|c|}
\hline Age Range & Class- room & Online & Video & Total \\
\hline $\begin{array}{l}\text { 18-25 years } \\
\text { Expected Count } \\
\text { Standardized Residual }\end{array}$ & $\begin{array}{c}486 \\
452.9 \\
1.6\end{array}$ & $\begin{array}{c}105 \\
136.3 \\
-2.7\end{array}$ & $\begin{array}{l}80 \\
81.8 \\
-.2\end{array}$ & 671 \\
\hline $\begin{array}{l}\text { 26-30 years } \\
\text { Expected Count } \\
\text { Standardized Residual }\end{array}$ & $\begin{array}{c}61 \\
79.6 \\
-2.1\end{array}$ & $\begin{array}{c}38 \\
24.0 \\
2.9\end{array}$ & $\begin{array}{c}19 \\
14.4 \\
1.2\end{array}$ & 118 \\
\hline $\begin{array}{l}\text { 31-35 years } \\
\text { Expected Count } \\
\text { Standardized Residual }\end{array}$ & $\begin{array}{c}15 \\
21.6 \\
-1.4\end{array}$ & $\begin{array}{l}14 \\
6.5 \\
2.9\end{array}$ & $\begin{array}{c}3 \\
3.9 \\
-.5\end{array}$ & 32 \\
\hline $\begin{array}{l}\text { 36-40 years } \\
\text { Expected Count } \\
\text { Standardized Residual }\end{array}$ & $\begin{array}{c}12 \\
14.2 \\
-.6\end{array}$ & $\begin{array}{c}7 \\
4.3 \\
1.3\end{array}$ & $\begin{array}{c}2 \\
2.6 \\
-.3\end{array}$ & 21 \\
\hline $\begin{array}{l}\text { More than } 40 \text { years } \\
\text { Expected Count } \\
\text { Standardized Residual }\end{array}$ & $\begin{array}{c}24 \\
29.7 \\
-1.0\end{array}$ & $\begin{array}{l}16 \\
8.9 \\
2.4\end{array}$ & $\begin{array}{c}4 \\
5.4 \\
-.6\end{array}$ & 44 \\
\hline $\begin{array}{l}\text { Total } \\
\quad \text { Expected Count }\end{array}$ & 598 & 180 & 108 & $\begin{array}{l}886 \\
886\end{array}$ \\
\hline
\end{tabular}

$\chi^{2}=43.81, d f=8, N=886, p<.001$

The results indicated a significant relationship existed when comparing age range and mode. For traditional college-aged students, those in the 18 to 25 year range, fewer than expected were recorded for the online mode. Conversely, a greater than expected number of online students were in the remaining older age ranges $(26$ years +$)$. Thus, older students had a preference for online delivery, while younger students had a negative preference for this mode.

Year in School of Student. A Pearson chi-square was conducted to examine whether significant relationships existed between year in school of the student and delivery mode selected. The results of the observed and expected frequencies are presented in Table 13.

The results indicated a significant relationship existed when comparing year in school and delivery mode. Results showed more than expected freshmen preferred the classroom mode and fewer than expected freshman preferred the online mode. Seniors exhibited the reverse preference, with fewer than expect seniors preferring the classroom mode and more than expected seniors preferring the online and video conference modes. 
Table 13: Chi-Square Test of Observed and Expected Frequencies by Year in School of Student and Delivery Mode

\begin{tabular}{|c|c|c|c|c|}
\hline Year in School & Class- room & Online & Video & Total \\
\hline Freshman & 196 & 20 & 21 & 237 \\
\hline Expected Count & 160.8 & 47.0 & 29.2 & \\
\hline Standardized Residual & 2.8 & -3.9 & -1.5 & \\
\hline Sophomore & 108 & 21 & 11 & 140 \\
\hline Expected Count & 95.0 & 27.8 & 17.3 & \\
\hline Standardized Residual & 1.3 & -1.3 & -1.5 & \\
\hline Junior & 113 & 46 & 22 & 181 \\
\hline Expected Count & 122.8 & 35.9 & 22.3 & \\
\hline Standardized Residual & -.9 & 1.7 & -.1 & \\
\hline Senior & 161 & 82 & 51 & 294 \\
\hline Expected Count & 199.5 & 58.3 & 36.2 & \\
\hline Standardized Residual & -2.7 & 3.1 & 2.5 & \\
\hline Total & & & & 852 \\
\hline Expected Count & 578.1 & 169 & 105 & 852.1 \\
\hline
\end{tabular}

Academic Major of Student. A Pearson chi-square was conducted to examine whether significant relationships existed between the academic major of the student and delivery mode choice. Caution should be exercised in interpreting the results, because two cells (13\%) had expected counts of less than 5. Table 14 displays the values on which the analysis was based.

Table 14: Chi-Square Test of Observed and Expected Frequencies by Academic Major of Student and Delivery Mode

\begin{tabular}{|c|c|c|c|c|}
\hline Major & Class- room & Online & Video & Total \\
\hline Accounting & 14 & 5 & 3 & 22 \\
\hline Expected Count & 14.8 & 4.5 & 2.7 & \\
\hline Standardized Residual & -.2 & .2 & .2 & \\
\hline Business & 52 & 13 & 5 & 70 \\
\hline Expected Count & 47.1 & 14.3 & 8.6 & \\
\hline Standardized Residual & .7 & -.3 & -1.2 & \\
\hline Hospitality Management & 73 & 38 & 37 & 148 \\
\hline Expected Count & 99.5 & 30.3 & 18.2 & \\
\hline Standardized Residual & -2.7 & 1.4 & 4.4 & \\
\hline Behavioral Science/ English & 43 & 11 & 7 & 61 \\
\hline Expected Count & 41.0 & 12.5 & 7.5 & \\
\hline Standardized Residual & .3 & -.4 & -.2 & \\
\hline Other & 413 & 114 & 57 & 584 \\
\hline Expected Count & 392.6 & 119.4 & 71.9 & \\
\hline Standardized Residual & 1.0 & -.5 & -1.8 & \\
\hline Total & & & & 885 \\
\hline Expected Count & 595 & 181 & 108.9 & 884.9 \\
\hline
\end{tabular}

$\chi^{2}=33.88, d f=8, N=888, p<.001$ 
The results indicated a significant relationship existed between academic major and delivery mode. The majority of students selected classroom as the preferred delivery mode, and those selecting classrooms tended to have indicated Other as their major. Those who selected online delivery also tended to have indicated Other as their major. However, a larger group than expected of the Hospitality Management majors selected the video conference as the preferred delivery mode.

Full-time Status of Student. A Pearson chi-square was conducted to examine whether significant relationships exist between student status, full-time or part-time, and delivery mode. Table 15 presents the values used in the analysis.

Table 15: Chi-Square Test of Observed and Expected Frequencies by Full-Time Status of Student and Delivery Mode

\begin{tabular}{|c|c|c|c|c|}
\hline Status & Class- room & Online & Video & Total \\
\hline Full Time & 544 & 135 & 90 & 769 \\
\hline Expected Count & 517.9 & 156.7 & 94.4 & \\
\hline Standardized Residual & 1.1 & -1.7 & -.5 & \\
\hline Part Time & 54 & 46 & 19 & 119 \\
\hline Expected Count & 80.1 & 24.3 & 14.6 & \\
\hline Standardized Residual & -2.9 & 4.4 & 1.1 & \\
\hline Total & & & & 888 \\
\hline Expected Count & 598 & 181 & 109 & 888 \\
\hline
\end{tabular}

$\chi^{2}=33.88, d f=2, N=888, p<.001$

The results showed that the majority of students selecting classroom as the delivery mode tended to fulltime students, as did those selecting online deliver and video conferencing delivery. However, fewer than expected part-time students preferred classroom delivery, while more than expected part-time students showed a preference for online delivery.

Summary. In terms of the relationship between demographic characteristics of students and preference for the three delivery modes, significant differences were found on most characteristics tested. Only gender and race/ethnicity showed no significant relationships to choice of delivery mode. The other four factors, age, year in school, academic major, and full-time status, were significantly related in some way to delivery mode.

\section{SUMMARY}

Effectiveness. For students, the findings showed significant differences existed on all the effectiveness measures between classroom and online delivery. Students in the classroom mode expressed greater satisfaction on all measures, except class size. On all other measures, the students were significantly more favorably disposed toward classroom delivery than the online delivery. Based on total effectiveness, the finding was significant that for students, classroom delivery was more effective than online delivery.

For students, the results of comparing the classroom mode with the video conference mode on the effectiveness measures revealed significant differences. Based on total effectiveness, the finding was significant that for students, classroom delivery was more effective than video conference delivery.

For students, the results of comparing the online mode and the video conference mode on the effectiveness measures were less revealing. The only significant difference between the two was on class size. This suggested that in the opinion of students, the video conference mode was less adaptable to accommodating any number of students than was the online mode. Otherwise, no significant differences on effectiveness were found between the two distance delivery modes investigated. 
Student Characteristics. The investigated demographic characteristics for students, gender, race/ethnicity, age, year in school, academic major, and full-time/part-time status, were found for the most part to be significantly related in some way to the student preference for one course delivery mode over another. These relationships included that younger students (18-25 years) were more likely than expected to prefer classroom delivery and less likely than expected to prefer online delivery, while older students $(26+$ years $)$ were more likely than expected to prefer online delivery. Freshmen students were more likely than expected to prefer classroom delivery and less likely than expected to prefer online delivery, while seniors were more likely than expected to prefer the online and video conference delivery and less likely that expect to prefer classroom delivery. Part-time students were more likely than expected to prefer online delivery and less likely than expected to prefer the classroom delivery.

\section{CONCLUSIONS}

From these findings, the major conclusion reached was that classroom was more effective than the two distance education modes investigated, online and video conference. Not only were there differences between the classroom and distance modes but, where measurable, these differences were significantly weighted in favor of the classroom delivery. However, no significant differences were found between the two distance education delivery modes.

The results should also be useful to leaders at other institutions of higher education. By applying the framework, developed for this study, to determining the effectiveness of the course delivery modes at their colleges and universities, institutional leaders can better understand the benefits associated with different undergraduate delivery modes. Prior to making decisions about the course delivery modes best suited to their institutions, leaders should request and apply effectiveness information. Once secured, this information will help leaders to make more informed decisions.

\section{UTILITY OF THE STUDY}

Although the results of this research may be delimited in terms of application to a single institution, this shortcoming is offset by the opportunity to compare the three delivery modes in a consistent environment. In addition, the framework developed for determining effectiveness could be used by other institutions of higher education for investigating the suitability of different delivery modes. Therefore, even though the results of the study may apply essentially to one institution, the procedures developed have potential greater utility, if they are applied to other settings with similar conditions.

\section{REFERENCES}

1. American Federation of Teachers. (2000). Distance education: Guidelines for general practice. Washington, DC: Author.

2. American Distance Education Consortium. (2003). Guiding principles for distance teaching and learning. Washington, DC: Author.

3. Daniel, J. S. (1999). Mega-universities and knowledge media. London: Kogan Page.

4. Institute of Higher Education Policy. (2000). Benchmarks for success in Internet-based distance education: Quality on the line. Washington, DC: National Education Association.

5. $\quad$ Levin, H. M., \& McEwan, J. P. (2001). Cost-effectiveness analysis ( $2^{\text {nd }}$ ed.). London: Sage.

6. National Education Association. (2000). A survey of traditional and distance learning higher education members of the National Education Association. Retrieved January 13, 2007, from http://www.nea.org/he/aboutthe/distance.htm

7. National Education Association. (2000). Benchmarks for success in Internet-based distance education. Washington, DC: Author. 